\title{
HERD BEHAVIOR IN USING MOBILE PAYMENT WITH UNIFIED THEORY OF ACCEPTANCE AND USE OF TECHNOLOGY (UTAUT2)
}

\author{
Rohmad Fuad Armansyah \\ Banking and Finance Diploma Program, Universitas Hayam Wuruk Perbanas (STIE Perbanas Surabaya), Indonesia \\ Corresponding author; Email: fuad@perbanas.ac.id
}

\begin{abstract}
The advancement of information technology, combined with increased bank competition, sparked innovation in non-cash payment options. In Indonesia, mobile payment services had grown in tandem with the rising usage of smartphones in the previous five years, resulting in a shift in financial behavior toward digitization. This study aimed to examine the financial herding behavior of using mobile payments using the Unified Theory of Acceptance and Use of Technology (UTAUT2) approach. The data used for the respondent is 355 Indonesian students who used the mobile payment application on a mobile device. The results found that the variable performance expectance and price value had a significant effect on the behavioral intention of users of mobile payment applications in Indonesia. Then behavioral intention was proven to significantly influence user behavior and herd behavior as a form of financial behavior deviation which was proven to affect performance expectations.
\end{abstract}

Keywords: Herd behavior, behavioral intention, usage behavior, UTAUT2, mobile payment.

\section{Introduction}

The payment method has evolved in tandem with the advancement of modern technology. The role of cash, which is known to the general public as a means of payment in general, has been replaced by payment system technology in a more effective and efficient form of payment. It is also supported by the Indonesian digital market, which accepts non-cash payment transactions. Transactions that are fast, safe, convenient, easy, and efficient are the reasons for the acceptance of this non-cash payment system, which has been further developed for transaction ease.

One of the financial sector technologies that is now widely used is the payment method that does not require the use of physical money, and this method uses a gadget or smartphone for transactions (mobile payment), making it easier to make financial transactions anywhere. Mobile payment services have become popular with the increasing use of smartphones. The increase has reached $70 \%$ in the last five years in Indonesia. Moreover, there are many choices of mobile payment applications for transactions. Based on data from Bank Indonesia, 38 mobile payments have received official permission. In 2018, mobile payment transactions in Indonesia reached USD 1.5 billion and are predicted to increase to USD 25 billion in 2023. Based on iPrice (2020), the use of GoPay has the highest level of usage compared to other electronic money such as e-money, t-cash, and flazz (Figure 1).

GoPay is one of the products from the first Decacorn startup in Indonesia. Go-Jek is a mobile payment application with the most active users in Indonesia. Even though the Go-Jek application is not classified as a financial application, $30 \%$ of total electronic money transactions in Indonesia come from GoPay. In February 2019, GoPay succeeded in achieving a transaction of USD 6.3 billion with a total of $70 \%$ of Go-Jek transactions using GoPay as a payment method. GoPay is also the main payment method for Go-Food, which is also the largest food delivery app in Southeast Asia.

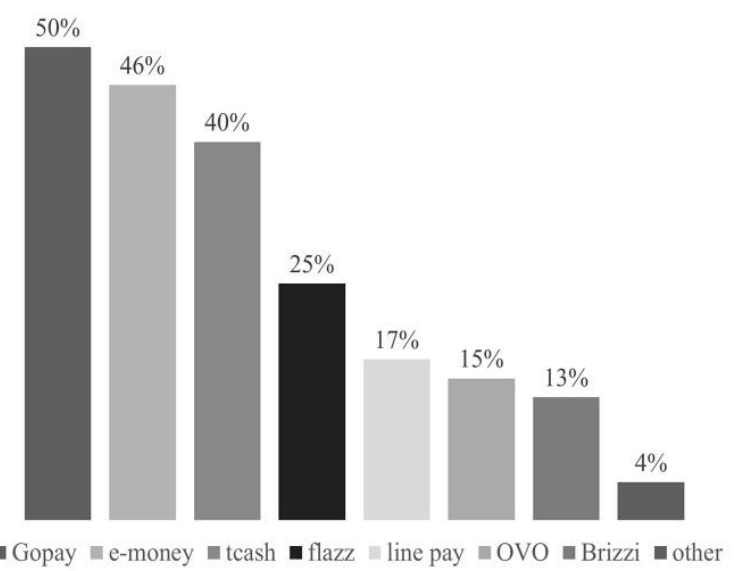

Source: iPrice, 2020

\section{Figure 1. Use of electronic money in Indonesia}

The development of communication technology also supports the development of non-cash transactions. Mobile devices such as smartphones have changed the user experience in transacting electronically, thus creating new alternatives for non-physical payments that users can use. The development also allows 
marketers to find new ways to sell their products through m-commerce and m-commerce becomes ecommerce, where business activities are carried out in a wireless environment using mobile devices (Zhang, Zhu, \& Liu 2012). This is due to the nature of people's online shopping as an early stage of the buying process (Ghose, Goldfarb, \& Han, 2011), where consumers look for products and judge according to their perceptions through wireless media either through smartphones or computer devices so that further developments leads to the reliability and features of the media.

User perception then becomes the main focus to develop the applications to meet the needs of the customers. Navigation constraints and network performance can also be considered as the main factors that disrupt the applications (online shopping) (Zhou, 2013), so that companies are investing heavily in redesigning their offers through shopping applications that can increase customer convenience, for example, integration of checkout purchases with mobile payment methods such as Apple Pay, Google Pay, virtual accounts from several banks, to mobile payment provider applications such as Gopay, OVO, Dana, Doku, Jenius, Link Aja, and others. As well as integration, privacy and security are considered when using mobile payments and online shopping. Regarding privacy, several studies show problems related to privacy and security, so that consumers do not complete their purchases through their mobile devices, so they tend to complete the shopping process on media or applications that have more trusted features (Luo, Li, Zhang, \& Shim, 2010).

Security features and application interfaces are of concern to users as well as application localization (Hoehle, Aljafari, \& Venkatesh, 2016). The localization of the application makes it easy for users to set the location automatically so they don't have to reset it at checkout. Coupled with issues related to malware, mobile network constraints, and content issues pose serious privacy and security risks for mobile users. Perceived risk has been shown to negatively to behavioral intentions and online consumer use behavior in recent studies. The increase of perceptions on security risks can lead to user resistance to the mobile app (Kuisma, Laukkanen, \& Hiltunen, 2007). Location-based services also raise issues of user privacy and risk perception (Zhou, 2013). The perceived risk among users is inherent in online transactions. Most studies in m-commerce focus on factors or drivers of acceptance rather than barriers (Groß, 2015), and hence the influence of barriers such as trust, privacy, and security issues on consumer behavior needs to be further explored. The perceived mobile threat will increase as more people use mobile devices for activities such as online shopping, bill payment, and playing games.

Despite the growing popularity of mobile payment apps, research in this area is limited to the fragmentation between benefits in business and app features that make it user-friendly. The first study group most often describes how mobile applications create value for users as well as the features of mobile applications that are attractive to users. The study confirms that the main features that differentiate the application from other competing technologies are the flexibility and portability of the application as well as the simultaneous delivery of real-time information to users. Research on the features that attract users to use mobile payment applications illustrates that clarity of information, the novelty of features, convenience in use, controls, application adjustments, and opportunities to provide feedback are attributes that can be used to attract users to the application, while interactivity is using the application makes the application attractive and can increase customer satisfaction and willingness to reuse the application (Kim, Wang, \& Malthouse, 2015). Other research shows that just like other cellular services, mobile applications are attractive to users because they offer instant connectivity, personalization, and timeliness everywhere (Legner, Urbach, \& Nolte, 2016). The application's ability to create networks and groups as well as save time with access to various communication channels as features that make the application attractive to users (Oghuma, Chang, Libaque-Saenz, Park, \& Rho, 2015). The application can also be enhanced by innovation and consumer gamification (Morosan \& DeFranco, 2016). Hong, Cao, and Wang (2017) show that social mobile applications depend on the size of the network that mobile applications have adopted so it is more useful and more enjoyable. Thus, users make judgments about perceived benefits and satisfaction under the influence of network externalities that can lead to herding behavior.

Herding behavior can also occur in the use of technology or in making decisions in adopting mobile payment applications, especially in terms of convenience and security features in transactions. This behavior will appear when faced with choices where these choices require prior knowledge for decision making. This knowledge can be obtained through information obtained independently or from other parties, friends, or relatives. The information is then processed to produce decisions following the expectations of the decision-makers. Making decisions related to herding behavior often brings unexpected results, such as being 
the cause of the financial crisis (Armansyah, 2018), or in the case of an initial public offering on the capital market, it can make shares underpricing (Ismiyanti \& Armansyah, 2010). Herding behavior in the use of mobile payment applications is closely related to following other activities while using mobile payment applications. Users will voluntarily or inadvertently create a mobile payment account, which will later be used in payment transactions. Riaz and Hunjra (2015) examined the influence of psychological factors on investor decisions and found that perceptions of risk were very influential in making investment decisions. Based on this, it leads to the idea of whether consumers use mobile payment applications based on their experience or based on suggestions from friends? in herd context.

This study focuses on herd behavior in the use of mobile payments using the UTAUT2 approach by integrating hedonic motivation, price value, and habits, and herd behavior in terms of performance expectations which are closely related to the use of mobile payment technology (Venkatesh, Morris, Davis, \& Davis, 2003; Venkatesh, Thong, \& Xu, 2012). So far it has been widely used to explain technology adoption behavior in many recent studies regarding the context of mobile trading behavior (Baptista \& Oliveira, 2015; Hew, Lee, Ooi, \& Lin, 2016; Teo, Tan, Ooi, Hew, \& Yew, 2015; Wang \& Wang, 2018; Wang, Cho, \& Denton, 2017) but in this study, UTAUT2 is used to study the acceptance and use of mobile payment applications in the context of online payments. Then, I supplement basic UTAUT2 with a herding perceived manifestation to explore the context of the information held in the use of mobile payments based on privacy risks, transaction security, and the adoption of mobile payments in Indonesia related to herd behavior based on cultural dimension and economic conditions.

Based on the existing description, this study develops behavioral intentions, herding behavior, and mobile payment application users using the Unified Theory of Acceptance and Use of Technology 2 (UTAUT2) from Venkatesh et al. (2012) to study the herd behavior that influences the adoption of mobile payments.

\section{Unified Theory of Acceptance and Use of Technology: UTAUT and UTAUT2}

According to Straub (2009) and Zuiderwijk et al. (2015), adoption theory studies the choices made by individuals to accept or reject technological innovations. Previous research has proposed several theoretical models in the field of new technology user acceptance with the technology acceptance model (TAM) being the dominant framework in the literature (Venkatesh et al., 2003). TAM-based research has been conducted in various contexts in e-commerce, online banking, and m-commerce. However, TAM deficiencies are also reported when considering the characteristics of consumer behavior. $\mathrm{Lu}$ and $\mathrm{Su}$ (2009) show that research using the technology acceptance model (TAM) has failed to consider negative emotions, belief in ability levels, and intrinsic motivation. Barki and Benbasat (2007) also recommend that researchers explore various constructs and models outside of TAM.

UTAUT was further developed by Venkatesh $e t$ al. (2003) by combining eight models of acceptance and use of information technology. Usage Behavior (UB) is influenced by Behavioral Intention (BI) with four core constructs that determine significantly, namely Performance Expectancy (PE), Effort Expectancy (EE), Facilitating Condition (FC), and Social Influence (SI). Venkatesh et al. (2012) then expanded UTAUT to UTAUT2 by adding specific factors from user behavior, namely Habit (HA), Hedonic Motivation $(\mathrm{HM})$, and Price Value (PV). UTAUT2 describes more differences in the use of Behavioral Intentions and technology compared to UTAUT. Venkatesh et al. (2016) further suggest that future research should enhance the application of UTAUT to various contexts of technology use. Therefore, this study adopts the UTAUT2 model because it is more comprehensive and suitable for explaining the behavior of mobile payment application users as well as developing the UTAUT2 model by adding herding behavior in the use of technology. This approach is used in achieving the research objectives. The constructs and hypotheses are presented in Figure 2.

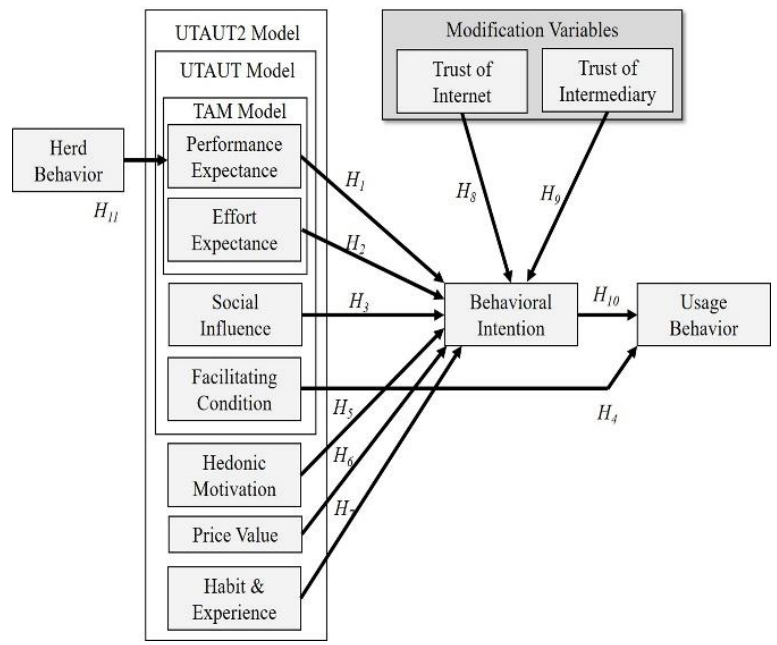

Figure 2. Research framework 
The model used in this study is the UTAUT2 model (Venkatesh et al., 2012) which is modified with two additional variables from Al-Sobhi, Weerakkody, and Al-Shafi, (2010) to determine user confidence in security. The main construct of UTAUT (Venkatesh et al., 2003) consists of two predictor variables from the acceptance model adopting the Technology Acceptance Model (TAM) construct according to Davis (1989), namely: (1) Performance Expectancy (PE), which is the level at which a person believes that with using the system will get benefits in doing its job, and the variable (2) Effort Expectancy (EE) of the perceived ease of use variable is explained by Venkatesh et al. (2003) as business expectations are the level of ease associated with use.

Venkatesh et al. (2003) in the UTAUT model added four constructs besides (1) PE and (2) EE is (3) Social Effect (SI) described by Al-Sobhi et al. (2010) as a person's level of importance towards other people's beliefs that he must use a new system, and (4) Facilitating Condition (FC) which is also described by Al-Sobhi et al. (2010) as a condition that helps individuals both organizationally and infrastructure in using the system and overcoming the obstacles faced when using the system.

Venkatesh et al. (2012) further developed the UTAUT2 model by analyzing additional variables that were considered to represent the factors of desire to use technology. These additions are (5) Hedonic Motivation (HM) which is defined as pleasure or happiness in using technology, (6) Price Value (PV), as the consumptive side that is influenced by the economy. This factor has a positive value when the perceived benefits of using technology are greater than the value for money and the Price Value is considered to have a positive impact on intention (technology acceptance). Referring to Venkatesh et al. (2012) which in the end include the last factor in UTAUT2 is (7) Habit $(\mathrm{H})$ with the consideration that the use of technology in a system can become a Habit automatically. (8) Trust of Internet (ToI) described by Al-Sobhi et al. (2010) is one of the modified variables as a representation of the extent to which users will use the internet to communicate and (9) Trust of Intermediary (TIM) is also a variable modified by Al-Sobhi et al. (2010) like the trust of technology users to intermediaries or service providers.

With so many mobile applications on the mobile market, there is a possibility of Herding Behavior happening, where it can be difficult to properly collect personal information about applications and they can make choices to imitate the adoptive behavior of others. In this way, the imitation of previous users helps minimize uncertainty and saves on information retrieval costs. Sun (2013) introduces that herding behavior occurs in two conditions: imitating others and ignoring one's information, where imitating others describes "the extent to which a person will follow other people's decisions when adopting technology" and "the degree to which a person ignores his own beliefs about technology. when making use decisions" (Sun, 2013). Based on that research, I also assume that herding behavior is built on two preconditions, namely imitating others and reducing or even ignoring their information. In this research, herding behavior will also be measured based on these two conditions. Several studies have shown the importance of herding behavior in the selection and use of technology such as downloading software products (Duan, Gu, \& Whinston, 2009), use of information systems (Sun, 2013), the positive influence of Herd Behavior on perceived usefulness, and the mediating effect of Herd Behavior on user satisfaction through perceived usefulness and showed the same results for social media mobile applications (Hong et al., 2017). These findings provide the basis for the formation of hypotheses in this study.

Behavioral Intention (BI) is an objective variable that shows the user's intention to carry out activities with technology, while Usage Behavior (UB) is an objective variable that shows the level of technology usage by the user.

\section{Performance Expectancy on Behavioral Intention}

Performance Expectancy is "the extent to which users believe that the use of technology will benefit them in carrying out certain activities" (Venkatesh et al., 2003). The construct was formulated in the previous UTAUT model and was developed by including conceptually similar variables from previous user acceptance studies into a variable called Performance Expectations. The Performance Expectancy variable will represent the perceived usefulness of users (Davis, 1989), extrinsic motivation (Davis, 1993), the relative advantage of Moore and Benbasat (1991) that builds on previous research on technology acceptance. The construction of performance expectance is shown to be a strong predictor of behavioral intention in Venkatesh et al. (2003; 2012). In the UTAUT and UTAUT2 models, the results show that Performance Expectancy has a significant effect on the user's decision to adopt the technology. In addition, research using the UTAUT model of Hew et al. (2016) explained that performance expectations play an important role in behavioral intention in the use of mobile applications. The results of these studies provide strong arguments for including performance expectations in the research model. 
Another reason for including this variable in the model is the expectation that it will represent efficiency, effectiveness, time/money savings, benefit seeking, etc. Yadav, Joshi, and Rahman (2015) explained that mobile apps create value for users through efficiency and effectiveness, by saving app users time and money. Kim et al. (2015) also mentioned convenience among features that can attract consumers to mobile applications and differentiate mobile applications from competing technologies. Oghuma et al. (2015) proved the important role of profit-seeking in mobile instant messaging app adoption. Based on these arguments, users want mobile payment applications to provide value to their lives and to perform better and more efficiently, which leads to the following hypothesis:

$H_{l}$ : Performance Expectancy has a positive effect on Behavioral Intention

\section{Effort Expectancy on Behavioral Intention}

Another variable in this model is Effort Expectance, which is defined by the UTAUT model as "the level of convenience associated with using the system" (Venkatesh et al., 2003). This variable is reported to be significant for new technology adoption in the original UTAUT model but only for inexperienced users and as users gain experience using the technology and learn more about it, the Effort Expectancy construct becomes insignificant for behavioral intentions (Venkatesh et al., 2003). The importance of the effort expectance construct is also evidenced in other technology acceptance models such as Davis (1989) using a construction called perceived ease of use to explain computer system adoption. In the UTAUT2 model, Venkatesh et al. (2012) also emphasized the importance of Effort Expectancy in the context of voluntary consumers.

The replication of TAM and models based on TAM and UTAUT provides much confirmation of the importance of Effort Expectancy and perceived ease of use for behavioral intentions for mobile technology and mobile applications. For example, Veríssimo (2016) emphasized that perceived ease of use was one of the constructs that determined the use of mobile banking applications, Taylor and Levin (2014) found that retail mobile application users were attracted to the simplicity of the technology and preferred to use less technology. Hew et al. (2016) reported the positive effect of small business expectations on behavioral intention to use mobile applications. The findings from previous studies are also a strong argument for me to hope that in this model performance expectations will also have a significant effect on Behavioral Intention.
Despite all the arguments described, we also find it fairly intuitive to assume that if users find the mobile application easy to use, they will have a higher intention of using the application. Kim et al. (2015) mention convenience, customization, and control among the main features that make mobile applications attractive to users, so it is logical that thanks to mobile applications that are convenient to use, adapt easily to customer needs, and allow larger users to control technology, users take a little effort to understand how to use it. In addition, research on the features of mobile applications that differentiate mobile applications from other technologies shows that customers want their mobile applications to be adaptive and work across a variety of devices (Cugola, Ghezzi, Pinto, \& Tamburrelli, 2012) which leads us to the conclusion that customers want to reduce their efforts to learn how to use them. the mobile app and become using the mobile app. Finally, research on mobile applications as a shopping and/or information-sharing technology by Taylor and Levin (2014) reported that mobile application users were interested in the simplicity of transactions and preferred mobile applications that had fewer annoying and irrelevant features. As a result, this study hypothesized that users would prefer to spend less time learning how to use mobile apps, particularly mobile payments, and would instead prefer to use mobile payment apps that they believe will be easier to use.

$H_{2}$ : Effort Expectancy has a positive effect on Behavioral Intention

\section{Social Influence on Behavioral Intention}

The third variable that will be introduced and tested in this model is social influence. This variable was introduced in the initial UTAUT model (Venkatesh et al., 2003). This social influence construct is similar to the subjective norm construct of the previous adoption model (Ajzen, 2002; Fishbein \& Ajzen, 1975; Taylor \& Todd, 1995; Venkatesh et al., 2003). The UTAUT model (Venkatesh et al., 2003) and the UTAUT2 model (Venkatesh et al., 2012) describe that social influence as "the degree to which an individual considers that an important person believes he or she should use the new system". In previous theoretical research, this construction has been shown to influence the intention to adopt the technology. For example, in Venkatesh et al. (2003) the social influence construct was shown to have a significant effect on behavioral intention in organizational settings. Furthermore, the development of UTAUT in UTAUT2, which examines the context of voluntary consumers, reports the positive influence of social influence on behavioral 
intention to use the mobile internet (Venkatesh et al., 2012). On the adoption of online trading in the Chinese and Malaysian markets, Chong, Chan, and Ooi, (2012) reported a significant influence of social influence on behavioral intention to adopt online trading. Wong Tan, Loke, and Ooi, (2014) also confirmed the positive influence of social influence on the intention to adopt mobile TV, but in their research, they have also generalized the concept to be more than what is called "others who matter" but also include social media and mass media in this concept. Finally, Yang and Forney (2013) also emphasized the significant influence of subjective norms on behavioral intention to use online shopping services. Based on the findings of the UTAUT2 model and referring to the results of previous studies. In this study, social influences are expected to have a positive impact on behavioral intentions when it comes to using mobile payment apps. The effect of this mechanism is expected to work in the daily life activities of family, friends, colleagues, and especially students who may use mobile payment applications and influence consumers' intention to adopt mobile payment applications.

$H_{3}$ : Social Influence has a positive effect on Behavioral Intention

\section{Facilitating Condition on Usage Behavior}

Another construct that will be tested in the model is the facilitating condition. This construct was first formulated in the PC Utilization model (Thompson, Higgins, \& Howell, 1991) and then used to formulate the facilitating condition construct in the UTAUT model (Venkatesh et al., 2003). In formulating this concept Venkatesh et al. (2003) also show how the Facilitating Condition is formed from the PC Utilization model of Thompson et al. (1991) is similar to Perceived Behavioral Control described by Ajzen (2002) and Taylor and Todd (1995) and Compatibility from Moore and Benbasat (1991). This study uses the definition of Facilitating Conditions developed by Venkatesh et al. (2003) as "the extent to which individuals believe that organizational and technical infrastructure exists to support system use". As formulated in the UTAUT model, the Facilitating Condition is hypothesized and is shown to only have a positive impact on user behavior. However, in the UTAUT2 model which focuses on the voluntary context of consumers, it is also assumed and confirmed that the Facilitating Condition has a positive effect on behavioral intention (Venkatesh et al., 2012). The main reason for this difference is the assumption that there is inadvertently the availability of training and support for users, whereas in the case of consumer market facilitation conditions can vary widely among technology providers. In this study, the argument makes a lot of sense and makes the concept of Facilitating Conditions more akin to perceived behavioral control in the TPB model. The reasons for including the construct facilitation conditions are supported by evidence from previous empirical research. Facilitating conditions are shown to have a significant positive effect on behavioral intention in the consumer context in the UTAUT2 model by Venkatesh et al. (2012).

Another study also confirmed the significant Facilitating Conditions for consumers' intention to adopt or not to adopt the services provided by information system providers. For example, Yang and Forney (2013) in a study on the adoption of mobile shopping, based on the development of TPB, showed a significant effect of Perceived Behavioral Control (a concept similar to the facilitating conditions in UTAUT2) on users' intention to adopt mobile shopping. In their research on the adoption of mobile shopping based on the adaptation of the UTAUT model, Yang and Forney (2013) also emphasized the importance of Facilitating Conditions for Behavioral Intention. Chong et al. (2012) in their study of mcommerce adoption showed a significant effect of facilitation conditions on behavioral intention. Later in the UTAUT2 model replication in Hew et al. (2016) also reported that high users' perceptions of facilitating conditions, such as online service support, mobile devices, internet connections, and so on, lead them to high-level behavioral intentions. In addition, a feature that distinguishes mobile applications from other information systems and makes mobile applications more attractive to users is the availability mechanism related to the relevant Facilitating Conditions so that they can be determinants for users to adopt or not adopt mobile applications.

One of the features of a mobile application that can be a strong facilitating condition for the user is the ability of the application to customize and personalize. For example, Kim et al. (2015) mention customization among features that increase users' desire to build relationships with mobile applications. Morosan and DeFranco (2016) also emphasized the importance of service personalization for the application of hotel mobile applications. In addition, since user experience in terms of mobile applications is highly dependent on the mobile device itself, the technical characteristics and features of a mobile phone can be a strong reason for users to consider adopting or not adopting a mobile application. For example, research on mobile applications has illustrated that mobile applications must be 
adaptive and work across different types of devices (Cugola et al., 2012). In addition, when mobile applications become more interactive, the environment in which mobile applications run can also become a condition that facilitates a strong intention to adopt or not adopt mobile applications (Legner et al., 2016). Lastly, some mobile applications rely heavily on access to the internet, while others can function perfectly without a connection to the internet. Although not all users have unrestricted access to the internet, the extent to which mobile applications depend on access to the internet can be another facilitation condition that can influence the intention to adopt a mobile application. Based on this empirical evidence and the reasons described above, the following hypothesis is proposed for this model:

$\mathrm{H}_{4}$ : Facilitating Condition has a positive effect on Usage Behavior.

\section{Hedonic Motivation on Behavioral Intention}

Another variable that is relevant for the mobile payment application adoption process, is Hedonic Motivation. Venkatesh et al. (2012) included this variable in the UTAUT2 model, which was specially designed for the context of voluntary consumers. Hedonic motivation will refer to the definition of Brown and Venkatesh (2005), in their research on technology adoption in households and used by Venkatesh et al. (2012) in the UTAUT2 model; "Hedonic motivation is the pleasure or pleasure one derives from using technology." Hedonic motivation in this study will represent the perceived value of enjoyment and will be used to measure the extent to which user expectations about joy and pleasure in using mobile payment applications can influence their intention to use it.

Evidence from a previous study by Venkatesh $e t$ al. (2012) confirmed their hypothesis that Hedonic Motivation is a significant predictor of consumer behavioral intention to use technology. A study on consumer cellular TV adoption Wong et al. (2014) reported that Hedonic Motivation is one of the most significant motivations indicating user intention in adopting mobile TV. Yang and Forney (2013) in their research on consumer technology anxiety in the application of cellular shopping also confirms that if the hedonic motivation is positive, the intention of consumers to use mobile shopping will also be significant. Lastly, Hew et al. (2016) reported that hedonic has a significant positive effect on Behavioral Intention to adopt mobile applications. In addition, Kim et al. (2015) describe clarity, novelty, and interactivity as attributes of mobile applications that attract consumers to use mobile applications. Morosan and DeFranco (2016) report that the adoption process of mobile applications can be significantly improved by the presence of game or game features that trigger users to play on mobile applications. Evidence for empirical research provides a strong basis for us to assume in the model that Hedonic Motivation is one of the determinants in shaping consumer behavioral intention to adopt mobile payment applications. It's possible that Hedonic Motivation was created for users via mobile payment apps in a variety of ways, and that it's largely dependent on mobile payment app developers. Also, the value of entertainment provided by mobile apps will be one of the major factors influencing users' intentions to use mobile payment apps. This leads to the following hypothesis:

$H_{5}$ : Hedonic Motivation has a positive effect on Behavioral Intention.

\section{Price Value to Behavioral Intention}

Another variable to be tested in this study is Price Value. This variable is introduced in the UTAUT2 model and can be defined as the "consumer cognitive tradeoff between the perceived benefits of an application and the monetary costs of using it" (Dodds, 1991). Or it can be said as a cost that consumers are willing to sacrifice to use or receive the benefits of a mobile application. The main reason for including this variable in the UTAUT2 model is that it represents the setting in which the user must bear the costs of adopting the technology themselves. Venkatesh $e t$ al. (2012) explain the mechanism of the effect of price value on behavioral intention Price value is considered positive when users perceive the benefits brought by technology to be higher than the monetary price of adopting technology. Theoretical research confirms the importance of price value on user behavioral intentions in technology adoption.

Venkatesh et al. (2012) reported the direct effect of price value on confirmed behavioral intention to adopt mobile internet. However, in empirical research, the importance of price value for technology services cannot be confirmed. For example, in a study on cellular TV adoption, Wong et al. (2014) reported the insignificant effect of price value on behavioral intention as indicated by the fact that users who see significant benefits regardless of price occur with a low need for new technology adoption will result in a low adoption rate of this technology. The inconsistencies in theoretical results can be attributed to certain types of technology and the price users pay for these technologies. In terms of mobile applications, it is very common for mobile applications to be offered in the market for free or at relatively low prices. Therefore, a very 
small price for using a mobile application that creates significant value for users will be reasonable and they will be ready to pay for it. At the same time, statistics show that the market is filled with mobile applications that are offered for free and also that users are cautious about upgrading their free mobile application to a paid version. This suggests that users are quite critical about the potential value the app will offer them and that the trade-off between potential benefits and price will be important for users when deciding to adopt a mobile payment app or not. These findings and arguments provide reasons to assume in this study that the price value will be an important factor in the process of using mobile payment applications.

$H_{6}$ : Price Value has a positive effect on Behavioral Intention.

\section{Habit on Behavioral Intention}

Mobile payment applications are usually made for daily use; therefore, it seems necessary to test the habit variable into the model. This variable is also introduced in the UTAUT2 model. Venkatesh et al. (2012) define a habit as "the extent to which people tend to perform behavior automatically based on learning and can be described as perceptual constructs that reflect the results of previous experiences". The UTAUT2 model confirmed the influence of Habit on Behavioral Intention in adopting the mobile internet, and the influence of Habit on intention to adopt technology was stronger for older men with broad experience. The same result was confirmed in Wong et al. (2014) in a mobile TV adoption study which reported that habits influence the sustainable use of information systems and that the daily use of new technology leads to an increase in habits which in turn supports the adoption of new technologies. In addition, in research on mobile app adoption in the Malaysian market, Hew et al. (2016) confirm that habit is the most significant driver for Behavioral Intention to adopt mobile applications. Nikou and Bouwman (2014) in a research on social networking sites, Habit was reported as an important predictor of Behavioral Intention to use social networking sites. Based on empirical findings from previous research, in the case of the mobile payment application adoption process, habits have a significant influence in determining behavioral intentions to adopt mobile payment applications because mobile applications are usually created for daily use, the user must use the application. over a while to try them out and discover their benefits, which contribute to the development of habits for using certain apps. Once a habit has been developed, it will be more difficult for users to switch to other applications, and the user will likely not even consider using another application. In this way, habits will contribute to the intention to adopt mobile payment applications.

$H_{7}$ : Habit has a positive effect on Behavioral Intention.

\section{Trust of Internet on Behavioral Intention}

Trust of Internet (ToI) is described in Al-Sobhi et al. (2010) as one of the modified variables that Trust of Internet represents the extent to which users will use the internet to communicate with the government. Trust in the internet is the extent to which users trust in the mobile payment application used, including account security, network, and legality to communicate with other parties. The higher the level of trust in using the mobile payment application, the more you will continue to use the mobile payment application. Based on this, the following hypothesis is proposed: $H_{8}$ : Trust of Internet has a positive effect on Behavioral Intention.

\section{Trust of Intermediary on Behavioral Intention}

Trust of Intermediary (TIM) which is also a modified UTAUT variable by Al-Sobhi et al. (2010) as trust in application intermediaries in communicating is the level at which individuals adopt intermediate channels (information systems) to communicate. This intermediary channel is an important part of the information exchange process, the level of data security and privacy is necessary so that user trust in this channel plays an important role in using the application. The higher the level of data security and privacy of the intermediary channel, the more confident in using the application so that users will continue to use the mobile payment application. Based on this, the following hypothesis is proposed:

$H_{9}$ : Trust of Intermediary has a positive effect on Behavioral Intention

\section{Behavioral Intention of Usage Behavior}

Behavioral intention indicates the intention of the technology used to use the product or service effectively. Venkatesh et al. (2012) define it as "what refers to the intention of effective use by consumers". The higher the intention or desire of the user is achieved, the higher the level of achievement of the use of technology by the user, so that the following hypothesis is proposed:

$H_{10}$ : Behavioral Intention has a positive effect on Usage Behavior. 


\section{Herd Behavior on Performance Expectance}

The word herding is basically from the word herd described the animal spirit to explain the naive optimism and confidence in the capital market. Herd, defined as the behavior of investors who tend to imitate or follow the behavior of other investors (Armansyah, 2018). According to Hirshleifer and Teoh (2003) herding behavior is associated with the people who (blindly) following the decisions of others. Herd behavior is reported as an important construct for the application of various technologies. Sun (2013) defines group behavior in technology adoption as "a phenomenon according to which people follow others when adopting technology, even when their personal information suggests doing something else." Herd behavior describes the socalled phenomenon "when each person does what everyone else is doing, even when their personal information suggests doing something completely different" (Banerjee, 1992), thus, depending on how people use and evaluate information, and information obtained from other people. When deciding to adopt a newly introduced mobile application, users may still lack personal information and experience with the application and will not rely solely on their personal information. Instead, they will more or less ignore their personal information and imitate the behavior of others by adopting more popular apps. Herd behavior is fundamentally different from other concepts describing social influence. Herd behavior depends on observing the behavior of others and is not influenced by what other people think about the final choice, for example, technology users (Sun, 2013).

The purpose of herd behavior is to provide the decisions that will give the best results for the user, regardless of whether these choices will be made based on imitating others. In the case of mobile payment apps, it is impossible to properly collect personal information about them and they can make choices to imitate the adoptive behavior of others. In this way, imitating previous users helps minimize uncertainty and saves costs in obtaining information. Sun (2013) introduces that herd behavior occurs in two conditions: imitating others and ignoring one's information, where imitating others describes "the extent to which a person will follow other people's decisions when adopting technology" and ignoring the information itself describes "the extent to which a person ignores his own beliefs about a particular technology when making adoption decisions" (Sun, 2013). Based on these findings, the assumption used is that herd behavior is built on two preconditions; imitating others and reducing the information itself. In this study, herd behavior will be measured based on these conditions.
Empirical studies report evidence of the importance of herd behavior in consumer choice and technology adoption, such as software download (Duan et al., 2009), information systems adoption (Sun, 2013). These findings form the basis of the hypothesis in this research model. Hong et al. (2017) conducted a study that reported the positive influence of Herd Behavior on perceived use and the mediating effect of Herd Behavior on user satisfaction through perceived use. A study by Hong et al. (2017) confirmed the findings for social mobile applications. This study assumes that the Herd Behavior effect is relevant not only for social mobile applications but also for mobile payment application technology as a whole, referring to Sun (2013) research. Sun (2013) revealed a significant positive effect of herd behavior on information system adoption. As such, herd behavior will have a positive influence on performance expectations because users who are unable to gather precise information about how useful the mobile payment app is to them will mimic previous user behavior. Following a model from Sun (2013) to measure herd behavior by imitating others, the following hypothesis is proposed:

$H_{11}$ : Herd behavior has a positive effect on performance expectance.

Then to determine the simultaneous influence of each variable Performance Expectancy, Effort Expectancy, Social Influence, Hedonic Motivation, Price Value, Habit, Trust of Internet and Trust of Intermediary on Behavioral Intention and its relationship to usage behavior, the following additional hypotheses are proposed:

$H_{12}$ : Performance Expectancy, Effort Expectancy, Social Influence, Hedonic Motivation, Price Value, Habit, Trust of Internet, and Trust of Intermediary have a positive effect on Behavioral Intention.

$H_{13}$ : Facilitating Conditions and Behavioral Intentions together have a positive effect on Usage Behavior.

\section{Research Method}

This study uses a quantitative approach in processing and testing data to obtain a clear picture of the phenomena that occur and to draw comprehensive conclusions according to theory. This study uses primary data obtained directly through e-questionnaires then processed descriptively and statistically using the PLS-SEM (Partial Least Square-Structural Equation Modeling) approach. The endogenous variables used in this study are Performance Expectancy, Behavioral Intention, and Usage Behavior. The measurement of this variable uses the approach from Venkatesh et al. (2012) with modification of UTAUT2 according to research 
by Ismarmiaty and Etmy (2018) and modification of adding herd behavior variables. Then, the exogenous variables used in this study are herd behavior, effort expectance, social influence, facilitating conditions, hedonic motivation, price value, habits, trust of the internet, trust of the intermediary.

This study uses students in the East Java region who use mobile payments on mobile devices as respondents with the sampling technique using purposive sampling with criteria; Higher education students in East Java, both state and private universities, who are at least 18 years old, respondents use one and/or several mobile payment applications on mobile devices such as OVO, Dana, GoPay, Link Aja, Jenius, Go Mobile. The data used are primary data with data collection techniques through distributing e-questionnaires. Measurements for the main dependent and independent variables in the model were collected using a 5-point Likert scale. No form of motivation or specific compensation was used to stimulate participants and participation in the survey on a voluntary and anonymous basis. The data analysis technique uses quantitative analysis by processing primary data obtained through distributing questionnaires. Data analysis in this study used descriptive analysis and statistical analysis through the outer model and inner model in PLS-SEM. PLS-SEM is designed to overcome problems in multiple regression. Technically it aims to produce a model that transforms a set of correlated explanatory variables into a new set of variables that are not mutually correlated. PLS-SEM analysis is divided into two stages, namely, the outer model and the inner model. The validity and reliability of the indicators on the latent variables can be seen using the outer model, while the test for the influence between latent variables can be seen through the inner model.

The outer model in this study is divided into two, namely, explanatory factor analyzes and confirmatory factor analyzes. Explanatory factor analysis (EFA) is used in the indicator measuring the latent variable is formative, while confirmatory factor analysis (CFA) is used in the indicator measuring the latent variable is reflective. In confirmatory factor analysis, an indicator is said to be valid if the loading factor value of the indicator measuring the latent variable is greater than 0.40 and the average variance extracted (AVE) value> 0.50 (Hair Jr., Matthews, Matthews, \& Sarstedt, 2017). The indicator is said to be reliable if the value of composite reliability (CR) and Cronbach alpha (CA) $>0.70$. Whereas in the explanatory factor analysis, the indicator is said to be valid if the loading factor value of the indicator measuring the latent variable is greater than 0.40 with a significance value < 0.05 , while the value of composite reliability (CR) and Cronbach alpha $>0.7$ then the indicator is said to be reliable.
The inner model describes the relationship between latent variables. The inner model is divided into two stages, namely hypothesis testing and the coefficient of determination. In hypothesis testing, the relationship between latent variables is said to be significant if the value of $p$-value $<\alpha=0.05$ or $t$-count $>1.96$. While the coefficient of determination, there are three criteria, namely, the influence between the latent variables are said to be strong if the value of $R^{2}>0.67$; moderate if $0.33<R^{2} \leq 0.67$; weak if the value of $0.19<R^{2} \leq 0.33$ and said to be very weak if the value of $R^{2} \leq 0.19$ (Chinn, 1998; Ghozali, 2014; Hwang \& Takane, 2004; Monecke \& Leisch, 2012).

\section{Result and Discussion}

This study uses a quantitative approach in processing and testing data so that problems regarding the herding of using mobile payments with the Unified Theory of Acceptance and Use of Technology (UTAUT2) approach can draw conclusions and discuss the issues raised. This study uses primary data for student respondents in the East Java region with a minimum age of 18 years using a mobile payment application. Data collection through e-questionnaire and obtained 355 data ready to be processed. The following is the description of the respondents.

Based on Table 1, most respondents are male respondents with 211 people (59.44\%) with an age range of $18-20$ years $(38.31 \%)$ who are domiciled or residing in Surabaya. Most of the respondents who filled out the questionnaire were students from private universities with 238 people or about $67.04 \%$ of the total respondents who had a monthly income of IDR $2,000,000$ to IDR 4,000,000 (65.07\%).

\section{Statistical Results}

The data was processed using WarpPLS version 6.0 through several stages with the Partial Least Square-Structural Equation Modeling (PLS-SEM) method and path estimate. This method is considered capable of overcoming problems in multiple regression to form a model that transforms a set of correlating explanatory variables into a new set of uncorrelated variables. The measurement model (outer model) obtained is then evaluated based on the substantive content model by comparing the relative size of the weight and the significance of the weight, then the inner model is evaluated by looking at the variance percentage and looking at the $R$-squared value and seeing the coefficient of the structural path. 
Table 1

Respondent Description

\begin{tabular}{|c|c|c|c|}
\hline Demographics & Category & Frequency & Percentage \\
\hline \multirow[t]{2}{*}{ Gender } & Male & 211 & $59.44 \%$ \\
\hline & Female & 144 & $40.56 \%$ \\
\hline \multirow[t]{3}{*}{ Age } & 18-20 years & 136 & $38.31 \%$ \\
\hline & $21-23$ years & 135 & $38.03 \%$ \\
\hline & 24 years and above & 84 & $23.66 \%$ \\
\hline \multirow[t]{2}{*}{ College Status } & State University & 117 & $32.96 \%$ \\
\hline & Private University & 238 & $67.04 \%$ \\
\hline \multirow[t]{3}{*}{ Allowance / Monthly Income } & Less than IDR 2,000,000 & 66 & $18.59 \%$ \\
\hline & IDR $2,000,000-$ IDR $4,000,000$ & 231 & $65.07 \%$ \\
\hline & More than IDR 4,000,000 & 58 & $16.34 \%$ \\
\hline \multirow[t]{19}{*}{ City of residence/ residence } & Surabaya & 125 & $35.21 \%$ \\
\hline & Sidoarjo & 80 & $22.54 \%$ \\
\hline & Kupang & 19 & $5.35 \%$ \\
\hline & Lamongan & 19 & $5.35 \%$ \\
\hline & Mojokerto & 19 & $5.35 \%$ \\
\hline & Tuban & 15 & $4.23 \%$ \\
\hline & Bojonegoro & 14 & $3.94 \%$ \\
\hline & Ende & 13 & $3.66 \%$ \\
\hline & NTB & 13 & $3.66 \%$ \\
\hline & Lumajang & 12 & $3.38 \%$ \\
\hline & Gresik & 10 & $2.82 \%$ \\
\hline & Malang & 5 & $1.41 \%$ \\
\hline & Sumenep & 3 & $0.85 \%$ \\
\hline & Bangkalan & 2 & $0.56 \%$ \\
\hline & Batu & 2 & $0.56 \%$ \\
\hline & Kediri & 1 & $0.28 \%$ \\
\hline & Nganjuk & 1 & $0.28 \%$ \\
\hline & Ponorogo & 1 & $0.28 \%$ \\
\hline & Tulungagung & 1 & $0.28 \%$ \\
\hline
\end{tabular}

\section{Outer Model}

The following is the result of the Partial Least Square regression.

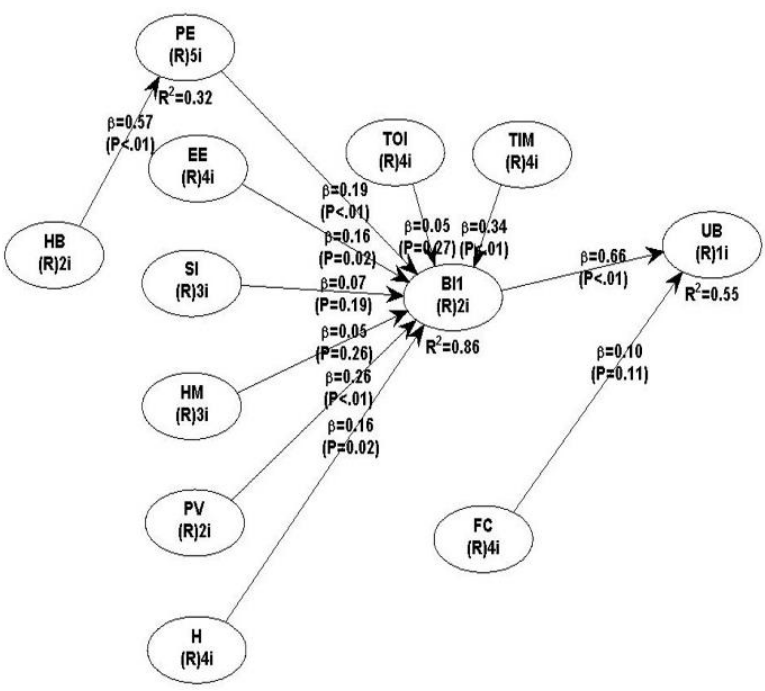

Figure 3. SEM-PLS model
The result shows that all factor loading values of the indicator have a value above 0.70 . Based on Figure 3 and Table 2 show that AVE value $>0.60$ and according to Chinn (1998) an indicator is said to have good reliability if the value is greater than 0.7 while the loading factor of 0.50 to 0.60 can still be maintained for a model that is still under development so that this result indicates that the validity criteria have been met. Table 2 also shows that the value of composite reliability and Cronbach alpha has a value above 0.70 , so these results indicate that the reliability criteria have been met. It can be concluded that the indicators PE1, PE2, PE3, PE4, PE5 can measure the Performance Expectancy variable well as well as EE1, EE2, EE3, EE4, SI1, SI2, SI3, FC1, FC2, FC3, FC4, HM1, HM2, HM3, PV1, PV2, H1, H2, H3, H4, TOI1, TOI2, TOI3, TOI4, TIM1, TIM2, TIM3, TIM4, BI1, BI2, HB1, HB2 also have a loading factor value above 0.70 so they can measure well the effort variable expectance, social influence, facilitating conditions, hedonic motivation, price value, habit and experience, trust of internet, trust of intermediary, behavioral intention, and herd behavior. 
Table 2

Outer Model

\begin{tabular}{lrrrr}
\hline & CR & CA & AVE & R-squared \\
\hline Performance & 0.92 & 0.89 & 0.70 & 0.32 \\
Expectancy & & & & \\
Effort Expectancy & 0.93 & 0.89 & 0.75 & \\
Social Influence & 0.92 & 0.87 & 0.79 & \\
Facilitating Condition & 086 & 0.78 & 0.61 & \\
Hedonic Motivation & 0.92 & 0.86 & 0.78 & \\
Price Value & 0.93 & 0.85 & 0.87 & \\
Habit & 0.94 & 0.91 & 0.79 & \\
Trust of Internet & 0.94 & 0.92 & 0.80 & \\
Trust of Intermediary & 0.91 & 0.87 & 0.72 & \\
Behavioral Intention & 0.82 & 0.56 & 0.69 & 0.86 \\
Herd Behavior & 0.93 & 0.84 & 0.86 & \\
Usage Behavior & 1,000 & 1,000 & 1,000 & 0.55 \\
\hline
\end{tabular}

\section{Inner Model}

The next stage of the PLS-SEM analysis is the structural model evaluation stage. At this stage, the results of full collinearity VIF, $p$-value, $R$-square, and path coefficient are seen to get the effect of each variable, either directly or indirectly. Based on Table 3, we can see that the $R$-square values for performance expectance, behavioral intention, and usage behavior are $0.32,0.86$, and 0.55 with $p$ values $<0.01(<0.00)$, respectively. This model also does not show multicollinearity because the VIF values are all below five. The predictive values of $\mathrm{PE}, \mathrm{BI}$, and $\mathrm{UB}$ are good because they have positive values above zero. The $R$ square value is in the interval 0.33 to 0.67 for usage behavior so that the influence of the variables is at a moderate level, while the performance expectations are in the interval 0.19 to 0.33 so that the influence is at a weak level. But for behavioral intention have an R-squared of 0.86 or is in the interval $R^{2}>0.67$ thus classified as having a strong influence.

The effect of performance expectance on behavioral intention was found to be significant, with a coefficient of 0.19 and a $p$-value $<0.00$. Based on these findings, hypothesis 1 is accepted, which means that there is a significant and positive influence between performance expectations on behavioral intention. Thus, the performance expectation of mobile payments can increase the behavioral intention of users of payment applications. This shows that mobile payment application users can feel the usefulness of the application both in terms of benefits, productivity, increased user performance, as well as helping to complete work faster to encourage users to achieve important things with the help of applications. In this study, performance expectance is proven to be a predictor of behavioral intention. The results of this study support the research by Venkatesh et al. (2012) that performance expectance is shown to be a predictor of behavioral intention and also supports the results of Davis (1989; 1993) and Moore and Benbasat (1991). This result is possible because users have expectations in using the mobile payment application and these expectations can be satisfied with the existing application features.

The effect of effort expectation on behavioral intention was found to be insignificant, with a coefficient of 0.16 and a $p$-value of 0.02 greater than 0.01. Based on these findings, hypothesis 2 is rejected, which means that there is no significant and positive effect of effort expectance on behavioral intention. Thus, the effort expectation of the mobile payment application cannot increase the behavioral intention of the user. These results indicate that the existing mobile payment application is still considered difficult to use, but when users gain experience in using technology and learn a lot it will make it easier to use, this is in line with the opinion of Venkatesh et al. (2003) stated that the effort expectance will be insignificant for behavioral intention. The results of this study also support Hew et al. (2016) and Cugola et al. (2012) which show that the effect of small effort expectations on behavioral intention is for mobile

Table 3

Path Analysis and Hypothesis Testing

\begin{tabular}{lcccc}
\hline Path & Coefficients & p-value & Effect Size & Conclusion \\
\hline Performance Expectancy $\rightarrow \cdot$ Behavioral Intention & 0.19 & $<0.00$ & 0.13 & Supported \\
Effort Expectancy $\rightarrow \cdot$ Behavioral Intention & 0.16 & 0.02 & 0.10 & Not Supported \\
Social Influence $\rightarrow \cdot$ Behavioral Intention & 0.07 & 0.19 & 0.04 & Not Supported \\
Facilitating Condition $\rightarrow \cdot$ Usage Behavior & 0.10 & 0.11 & 0.06 & Not Supported \\
Hedonic Motivation $\rightarrow \cdot$ Behavioral Intention & 0.05 & 0.26 & 0.04 & Not Supported \\
Price Value $\rightarrow \cdot$ Behavioral Intention & 0.26 & $<0.00$ & 0.18 & Supported \\
Habit \& Experience $\rightarrow \cdot$ Behavioral Intention & 0.17 & 0.02 & 0.12 & Not Supported \\
Trust of Internet $\rightarrow \cdot$ Behavioral Intention & 0.05 & 0.27 & 0.03 & Not Supported \\
Trust of Intermediary $\rightarrow \cdot$ Behavioral Intention & 0.34 & $<0.00$ & 0.23 & Supported \\
Behavioral Intention $\rightarrow \cdot$ Usage Behavior & 0.66 & $<0.00$ & 0.49 & Supported \\
Herd Behavior $\rightarrow \cdot$ Performance Expectance & 0.57 & $<0.00$ & 0.32 & Supported \\
\hline
\end{tabular}


application users and users who want the application to be more adaptive and functional. The results of this study do not support the previous study of ArenasGaitán, Peral-Peral, and Ramón-Jerónimo (2015) which shows that the effort expectance affects the use of internet banking, this is possible because of the different technology between internet banking and mobile payment where internet banking is more adaptive to the use of personal computers in its application, while mobile payments are more use on smartphones.

The influence of Social Influence on Behavioral Intention was found to be insignificant with a coefficient of 0.07 with a $p$-value of 0.19 greater than 0.01 , so hypothesis 3 is rejected. The findings of this study do not support the results of Chong et al. (2012), which show that social influence has a significant influence on behavioral intention to adopt online trading. This is possible because users are not influenced by people who influence them in using or adopting mobile payments, users feel the need to use the application.

The effect of the facilitating condition on usage behavior was found to be insignificant, with a coefficient of 0.10 and a $p$-value of 0.11 . Based on these findings, hypothesis 4 is rejected, which means that there is no significant and positive effect of facilitating conditions on usage behavior. Thus, improving the facilitating condition does not affect the usage behavior of mobile payment application users. This shows that in an unintentional condition, users feel that there is a lack of information and training that supports the use of the application. These results confirm Arenas-Gaitán et al. (2015) but not in line with research conducted by Chong et al. (2012); Hew et al. (2016); Venkatesh et al. (2012); Yang and Forney (2013) which suggests that facilitating conditions influence behavioral intentions in the use of technology.

The influence of hedonic motivation on behavioral intention was found to be insignificant, with a coefficient of 0.05 and a p-value of 0.26 . Based on these findings, hypothesis 5 is rejected, which means that there is no significant and positive effect of hedonic motivation on behavioral intention. Thus, increasing hedonic motivation does not affect the behavioral intention of mobile payment application users. These results confirm Arenas-Gaitán et al. (2015) stated that hedonic motivation does not affect behavioral intention in using mobile payments, and does not support the results of Venkatesh et al. (2012) and Wong et al. (2014) in the adoption of mobile TV, Yang and Forney (2013) in mobile shopping. This difference in results is possible because respondents in this study felt that the use of mobile payments was necessary to use and not because of pleasure.
The effect of price value on behavioral intention was found to be significant with a coefficient of 0.26 and significant ( $p$-value $<0.00$ ), so hypothesis 6 is accepted. The findings of this study confirm the results of a study conducted by Dodds (1991), Arenas-Gaitán et al. (2015), and Venkatesh et al. (2012), which show the effect of price value on the behavioral intention of using mobile payments. This shows that mobile payment users are not burdened by the costs involved in using the mobile payment application.

The influence of habit on behavioral intention was found to be insignificant, with a coefficient of 0.17 and a $p$-value of 0.02 greater than 0.01 . Based on these findings, hypothesis 7 is rejected, which means that there is no significant and positive influence between habit and behavioral intention. Thus, increasing habit does not affect the behavioral intention of using mobile payments. As can be seen in Table 3, mobile payment users feel the need to use applications only when the application is needed, so that users do not feel the need to get used to using mobile payments. This is possible because mobile payments are required for payment transactions only, and so far the existing mobile payment applications do not offer other features so that users can use the application for a long time. These results are not in line with the results of research by Arenas-Gaitán et al. (2015), Nikou and Bouwman (2014), and Wong et al. (2014).

The influence of trust of the internet on behavioral intention was found to be insignificant, with a coefficient of 0.05 and a p-value of 0.27 greater than 0.01 . Based on these findings, hypothesis 8 is rejected, which means that there is no significant and positive effect of trust in the internet on behavioral intention. Thus, an increase in trust in the internet does not affect the behavioral intention of mobile payment application users. These results confirm Ismarmiaty and Etmy (2018) and do not support the results of Al-Sobhi et al. (2010). This difference in results is possible because respondents in this study felt that the use of the internet for mobile payments was still insecure in terms of account security, network, and personal data.

The effect of trust of intermediary on behavioral intention was found to be significant, with a coefficient of 0.34 and $p$-value $<0.00$. Based on these findings, hypothesis 9 is accepted, which means that the trust of intermediaries has a positive effect on behavioral intention. Thus, the increase in trust of intermediaries affects the behavioral intention of mobile payment application users. These results confirm by Al-Sobhi et al. (2010) and Ismarmiaty and Etmy (2018) that the trust of intermediaries affects behavioral intention in using mobile payments. In this study, respondents still 
trust service providers because mobile payment applications in Indonesia are mostly managed by banks.

The effect of behavioral intention on usage behavior was found to be significant, with a coefficient of 0.66 and a $p$-value $<0.00$. Based on these findings, hypothesis 10 is accepted, which means that there is a significant and positive influence on behavioral intention to user behavior. Thus, the increased behavioral intention affects the behavioral intention of mobile payment application users. These results confirm by Ismarmiaty and Etmy (2018) and Venkatesh et al. (2012) stated that behavioral intention affects usage behavior in the use of mobile payments. This result occurs because respondents feel that the purpose of using mobile payments has been accommodated appropriately, which is used for payment activities.

The effect of herd behavior on performance expectance was found to be significant, with a coefficient of 0.57 and p-value $<0.00$. Based on these findings the hypothesis 11 is accepted, which means there is a significant and positive effect of herd behavior towards performance expectance, but if you see the value of $R^{2}$ of 0.32 (Table 3 ) are in between $0.19<R^{2} \leq 0.33$ means having a weak relationship. Thus, an increase in herd behavior affects the performance expectations of mobile payment application users. These results confirm by Duan et al. (2009), Hong et al. (2017), and Sun (2013) that herd behavior affects performance expectations in the use of mobile payments. Based on these findings, it shows that respondents who use mobile payment especially students in Indonesia who prefer to use the mobile payment application follow the recommendations of other users who have close relationships with respondents such as relatives or close friends, although the effect is weak, this study can capture the phenomenon of herding behavior in using mobile payments.

This was also shown by $37.18 \%$ or 132 respondents who answered that they had followed the recommendations for using mobile payments from the closest person. Conditions like this occur can be caused by respondents who are still relatively young (students) and lack experience in the use of technology for payments, so that suggestions from people closest to being trusted for the use of mobile payments.

The effect of performance expectance, effort expectance, social influence, hedonic motivation, price value, habit, trust of internet, and trust of intermediary together on behavioral intention was found to be significant, with an $R$-squared value of 0.86 (Table 3, Figure 3 ) and $p$-value $<0.00$. Based on these findings, hypothesis 12 is accepted, which means that there is a significant and positive influence on performance expectation, effort expectance, social influence, hedonic motivation, price value, habit, trust of the internet, and trust of intermediary on behavioral intention. Based on the value of $R^{2}=0.86$, which is at $R^{2}>0.67$ thus classified as having a strong influence so that it can be said that Behavioral Intention is influenced by $86.30 \%$ by Performance Expectancy, Effort Expectancy, Social Influence, Hedonic Motivation, Price Value, Habit, Trust of Internet and Trust of Intermediary, while the rest is influenced by variables outside the research.

The effect of facilitating condition and behavioral intention together on usage behavior was found to be significant, with an $R$-squared value of 0.55 and a $p$-value $<0.00$. Based on these findings, hypothesis 13 is accepted, which means that together facilitating conditions and behavioral intention have a significant and positive influence on user behavior. Thus, facilitating conditions and behavioral intention are two important factors that influence user behavior in the use of mobile payment applications.

\section{Conclusions and Implications}

Based on the findings of the research, it is possible to conclude that the variable performance expectations and price values have a significant effect on the behavioral intentions of mobile payment application users in Indonesia. Second, the relationship between behavioral intentions has been shown to significantly influence mobile payment usage behavior. Then the herd behavior as a form of financial behavior deviation is proven to affect performance expectations so that students as users of mobile payment applications in Indonesia are still influenced by opinions /suggestions from relatives or close friends in choosing and using mobile payment applications, not fully choosing and using the application themselves. This is possible because respondents are students who may have little experience in using mobile payments. These findings also adding theoretical contributions to existing research on herd behavior and prove that close relationships among users lead to herd behavior and influences performance expectations in using mobile payment applications, thereby broadening the theory of technology user behavior in mobile payments.

The findings of this study also have implications for practitioners, especially for mobile payment service providers. The results show that users pay attention to the performance of mobile payment applications and the costs required to use mobile payment technology, including the trust of intermediary to be the basis for 
trust in application use, this can be the basis for the behavioral intentions of mobile payment application users. It should also be noted, users pay attention to the opinions of relatives or close friends when deciding to use a mobile payment application so that service providers can use it for promotional activities, although this still requires more in-depth research.

Suggestions that can be conveyed following the development of this research are first, to raise more issues regarding financial behavior deviations because these factors are still considered the main triggers for behavior that affect the market besides the big five personality approach and the OCEAN model can also be used to develop this research so that able to provide various results for future scientific developments. Second, users are quite satisfied with the services provided by mobile payment providers and place an important role in trust in the provider, it's just that there is still the desire of users who are less informed such as information about deposits or other investments and evaluation of the use of funds during transactions, so it would be better if the service providers also provide useful information regarding this. As well as additional features for users who want to develop their financial management with features such as self-organizers to facilitate the management of their investments and funds.

This study has several limitations. First, research data is collected through respondents who respond to electronic questionnaires distributed through forums or groups as well as email in the hope of reaching respondents according to the specified criteria. Thus, this study may not represent all mobile payment application users in Indonesia. Future research can collect data from various sources, such as through system user discussion forums and crosscultural studies. Second, this study focuses on the benefits of using technology, especially mobile payment by adding the herd behavior model as a factor in financial behavior deviation that is considered to determine the use of payment applications. Future research can develop more detailed models that can explain more factors related to financial behavior. The use of other approaches is also suggested to develop this research to achieve more renewable research, which can overcome existing limitations.

\section{References}

Ajzen, I. (2002). Perceived behavioral control, selfefficacy, locus of control, and the theory of planned behavior. Journal of Applied Social Psychology, 32(4), 665-683. https://doi.org/10. 1111/j.1559-1816.2002.tb00236.x
Al-Sobhi, F., Weerakkody, V., \& Al-Shafi, S. (2010). The role of intermediaries in facilitating e-government diffusion in Saudi Arabia. Proceedings of the European, Mediterranean and Middle Eastern Conference on Information Systems: Global Information Systems Challenges in Management, EMCIS 2010, 1-17.

Arenas-Gaitán, J., Peral-Peral, B., \& Ramón-Jerónimo, M. A. (2015). Elderly and internet banking: An application of UTAUT2. Journal of Internet Banking and Commerce, 20 (1), 1-23.

Armansyah, R. F. (2018). Herd behavior and Indonesian financial crisis. Journal of Advanced Management Science, 6(2), 86-89. https:// doi.org/10.18178/joams.6.2.86-89

Banerjee, A. V. (1992). A simple model of herd behavior. The Quarterly Journal of Economics, 107(3), 797-817. https://doi.org/10.2307/21 18364

Baptista, G., \& Oliveira, T. (2015). Understanding mobile banking: The unified theory of acceptance and use of technology combined with cultural moderators. Computers in Human Behavior, 50, 418-430. https://doi.org/10.101 6/j.chb.2015.04. 024

Barki, H., \& Benbasat, I. (2007). Quo vadis, TAM? Journal of the Association for Information Systems, 8(4), 211-218. http://dx.doi.org/10 .17705/ 1jais.00126

Brown, S. A., \& Venkatesh, V. (2005). Model of adoption of technology in households: A baseline model test and extension incorporating household life cycle. MIS Quarterly, 29(3), 399-426 https://doi.org/10.2307/251 48690

Chinn, W. W. (1998). The partial least squares approach to structural equation modelling. modern. In G. A. Marcoulides (Ed.), Modern methods for business research (pp. 295 -336). Lawrence Erlbaum Associates Publishers.

Chong, A. Y. L., Chan, F. T. S., \& Ooi, K. B. (2012). Predicting consumer decisions to adopt mobile commerce: Cross-country empirical examination between China and Malaysia. Decision Support Systems, 53(1), 34 -43. https://doi.org/10.1016/ j.dss.2011.12.0 01

Cugola, G., Ghezzi, C., Pinto, L. S., \& Tamburrelli, G. (2012). Self-motion: A declarative approach for adaptive service-oriented mobile applications. Journal of Systems and Software, 85(8), 17091728. https://doi.org/10.1016/j. jss.2013.10.057

Davis, F. D. (1989). Perceived usefulness, perceived ease of use, and user acceptance of information technology. MIS Quarterly: Management Information Systems, 13(3), 319-339. https://doi.org/ $10.2307 / 249008$ 
(1993). User accepta nce of information technology: System characteristics, user perceptions, and behavioral impacts. International Journal of Man-Machine Studies, 38(3), 475-487. https://doi. org/10.1006/imms.1993.1022

Dodds, W. B. (1991). In search of value: How price and store name information influence buyers' product perceptions. Journal of Consumer Marketing, 8(2), 15-24. https://doi.org/10.1108/0736 3769110034974

Duan, W., Gu, B., \& Whinston, A. B. (2009). Informational cascades and software adoption on the internet: An empirical investigation. MIS Quarterly: Management Information Systems, 33(1), 23-48. https://doi.org/10.2307/ 20650277

Fishbein, M., \& Ajzen, I. (1975). Belief, attitude, intention, and behavior: An introduction to theory and research. Reading, MA: Addison-Wesley.

Ghose, A., Goldfarb, A., \& Han, S. P. (2011). How is the mobile internet different? Search costs and local activities. Presented in The 2011 International Conference on Information Systems. https://doi.org/10.1287/isre.1120.0 453

Ghozali, I. (2014). Structural equation modeling, metode alternatif dengan partial least square (PLS). Semarang: Badan Penerbit Universitas Diponegoro.

Groß, M. (2015). Exploring the acceptance of technology for mobile shopping: An empirical investigation among Smartphone users. International Review of Retail, Distribution and Consumer Research, 25(3), 215-235. https://doi.org/ 10.1080/09593969.2014.988280

Hair Jr., J. F., Matthews, L. M., Matthews, R. L., \& Sarstedt, M. (2017). PLS-SEM or CB-SEM: updated guidelines on which method to use. International Journal of Multivariate Data Analysis, 1(2), 107. https://doi.org/10.1504/IJMDA. 2017.087624

Hew, J. J., Lee, V. H., Ooi, K. B., \& Lin, B. (2016). Mobile social commerce: The booster for brand loyalty? Computers in Human Behavior, 59, 142-154. https://doi.org/10.1016/j.chb.2016.01. 027

Hirshleifer, D., \& Teoh, S. H. (2003). Herd Behaviour and Cascading in Capital Markets: A Review and Synthesis. European Financial Management, 9(1), 25-66. https://doi.org/10.1111/1468-036X. 00207

Hoehle, H., Aljafari, R., \& Venkatesh, V. (2016). Leveraging Microsoft's mobile usability guidelines: Conceptualizing and developing scales for mobile application usability. International
Journal of Human-Computer Studies, 89, 35-53. https://doi.org/10.1016/j.ijh cs.2016.02.001

Hong, H., Cao, M., \& Wang, G. A. (2017). The effects of network externalities and herding on user satisfaction with mobile social apps. Journal of Electronic Commerce Research, 18(1), 18-31.

Hwang, H., \& Takane, Y. (2004). Generalized structured component analysis. Psychometrika, 69, 81-99. https://doi.org/10.1007/B F02 295841

iPrice. (2020). The map of e-commerce in Indonesia. Retrieved April 10,2 020, from https://iprice. co.id/insights/mapofecommerce/

Ismarmiaty, I., \& Etmy, D. (2018). Model pendekatan UTAUT2 modifikasi pada analisis penerimaan dan penggunaan teknologi e-government di Nusa Tenggara Barat. MATRIK: Jurnal Manajemen, Teknik Informatika dan Rekayasa Komputer, 18(1), 106-114. https://doi.org/10.30812/matrik. v18i1. 347

Ismiyanti, F., \& Armansyah, F. (2010). Motif go public, herding, ukuran perusahaan, dan underpricing pada pasar modal Indonesia. Jurnal Manajemen Teori Dan Terapan, 1, 20-42.

Kim, S. J., Wang, R. J. H., \& Malthouse, E. C. (2015). The effects of adopting and using a brand's mobile application on customers' subsequent purchase behavior. Journal of Interactive Marketing, 31(August), 28-41. https://doi.org/10. 1016/j.intmar.2015.05.004

Kuisma, T., Laukkanen, T., \& Hiltunen, M. (2007). Mapping the reasons for resistance to Internet banking: A means-end approach. International Journal of Information Management. https://doi. org/10.1016/j.ijinfomgt.20 06.08.006

Legner, C., Urbach, N., \& Nolte, C. (2016). Mobile business application for service and maintenance processes: Using ex-post evaluation by end-users as input for iterative design. Information and Management, 53(6), 817-831. https://doi.org/10. 1016/j.im.2016.03.0 01

Lu, H. P., \& Su, P. Y. J. (2009). Factors affecting purchase intention on mobile shopping websites. Internet Research, 19, 442-458. https: //doi.org/ 10.1108/10662240910981399

Luo, X., Li, H., Zhang, J., \& Shim, J. P. (2010). Examining multi-dimensional trust and multifaceted risk in initial acceptance of emerging technologies: An empirical study of mobile banking services. Decision Support Systems, 49 (2), 222-234. https://doi.org/10.1016/j.dss.2010. 02.008

Monecke, A., \& Leisch, F. (2012). SemPLS: Structural equation modeling using partial least squares. 
Journal of Statistical Software, 48 (3), 1-32. https://doi.org/10.18637/jss.v048. i03

Moore, G. C., \& Benbasat, I. (1991). Development of an instrument to measure the perceptions of adopting an information technology innovation. Information Systems Research, 2(3), 173-239. https://doi.org/10.1287/isre.2.3.192

Morosan, C., \& DeFranco, A. (2016). Investigating American iPhone users' intentions to use NFC mobile payments in hotels. Information and Communication Technologies in Tourism, 427440. https://doi.org/10.1007/978-3-319-282312_31

Nikou, S., \& Bouwman, H. (2014). Ubiquitous use of mobile social network services. Telematics and Informatics, 31(3), 422-433. https://doi.org/10. 1016/j.tele.2013.11.002

Oghuma, A. P., Chang, Y., Libaque-Saenz, C. F., Park, M. C., \& Rho, J. J. (2015). Benefit-confirmation model for post-adoption behavior of mobile instant messaging applications: A comparative analysis of KakaoTalk and Joyn in Korea. Telecommunications Policy, 39 (8), 658-677. https://doi.org/10.1 016/j.telpol.2015.07.009

Riaz, L., \& Hunjra, A. (2015). Relationship between psychological factors and investment decision making: The mediating role of risk perception. Pakistan Journal of Commerce and Social Sciences (PJCSS), 9(3), 968-981.

Straub, E. T. (2009). Understanding technology adoption: Theory and future directions for informal learning. Review of Educational Research, 79(2), 625-649. https://doi.org/10.3102/00346543083 25896

Sun, H. (2013). A longitudinal study of herd behavior in the adoption and continued use of technology. MIS Quarterly: Management Information Systems, 37(4), 1031-1041. https://doi.org/10.25 300/MISQ/2013/37.4.02

Taylor, D. G., \& Levin, M. (2014). Predicting mobile app usage for purchasing and information-sharing. International Journal of Retail and Distribution Management, 42(8), 759-774. doi: 10.1108/ IJRDM-11-2012-0108

Taylor, S., \& Todd, P. (1995). Assessing IT usage: The role of prior experience. MIS Quarterly: Management Information Systems, 19(4), 561-570. https://doi.org/10.2307/249633

Teo, A. C., Tan, G. W. H., Ooi, K. B., Hew, T. S., \& Yew, K. T. (2015). The effects of convenience and speed in m-payment. Industrial Management and Data Systems, 115(2), 311-331. https://doi. org/10.1108/IMDS-08-201 4-0231
Thompson, R. L., Higgins, C. A., \& Howell, J. M. (1991). Personal computing: Toward a conceptual model of utilization. MIS Quarterly, 15 (1), 125-143 https://doi.org/10.2307/249 443

Venkatesh, V., Morris, M. G., Davis, G. B., \& Davis, F. D. (2003). User acceptance of information technology: Toward a unified view. MIS Quarterly: Management Information Systems, 27(3), 425-478. https://doi.org/10. $2307 / 30036540$

Venkatesh, V., Thong, J. Y. L., \& Xu, X. (2012). Consumer acceptance and use of information technology: Extending the unified theory of acceptance and use of technology. MIS Quarterly: Management Information Systems, 36 (1), 157-178. https://doi.org/10.230 7/414104 12

------ (2016). Unified theory of acceptance and use of technology: A synthesis and the road ahead. Journal of the Association of Information Systems, 17(5), 328-376. https://doi. rg/10.17705/1jais. 00428

Veríssimo, J. M. C. (2016). Enablers and restrictors of mobile banking app use: A fuzzy set qualitative comparative analysis (fsQCA). Journal of Business Research, 69(11), 5456-5460. https://doi. org/10.1016/j.jbusres.2016 .04.155

Wang, G., \& Wang, Y. (2018). Herding, social network, and volatility. Economic Modelling, 68, 74-81. https://doi.org/10.1016/j.econmod.2017. 04.018

Wang, M., Cho, S., \& Denton, T. (2017). The impact of personalization and compatibility with past experience on e-banking usage. International Journal of Bank Marketing, 35(1), 45-55. https://doi.org/10.1108/IJBM-04 -2015-0 046

Wong, C. H., Tan, G. W. H., Loke, S. P., \& Ooi, K. B. (2014). Mobile TV: A new form of entertainment? Industrial Management and Data Systems, 114 (7), 1050-1067. https://doi.org /10.1108/IMDS-05-2014-0146

Yadav, M., Joshi, Y., \& Rahman, Z. (2015). Mobile social media: The new hybrid element of digital marketing communications. Procedia - Social and Behavioral Sciences, 189, 335-343. https://doi.org/10.1016/j.sbspro.2015.0 3.229

Yang, K., \& Forney, J. C. (2013). The moderating role of consumer technology anxiety in mobile shopping adoption: Differential effects of facilitating conditions and social influences. Journal of Electronic Commerce Research, 14(4), 334-347.

Zhang, L., Zhu, J., \& Liu, Q. (2012). A meta-analysis of mobile commerce adoption and the moderating effect of culture. Computers in Human 
Behavior, 28(5), 1902-1911. https://doi.org/10. 1016/j.chb.2012.05.008

Zhou, T. (2013). An empirical examination of the determinants of mobile purchase. Personal and Ubiquitous Computing, 17(1), 187-195. https://doi.org/10.1007/s00779-011-0485-y
Zuiderwijk, A., Janssen, M., \& Dwivedi, Y. K. (2015). Acceptance and use predictors of open data technologies: Drawing upon the unified theory of acceptance and use of technology. Government Information Quarterly, 32 (4), 429-440. https://doi.org/10.1016/j.g iq .2015.09.005 